\title{
Impact of secondary education reform on tertiary students' generic competencies: A case study of associate degree freshmen in Hong Kong
}

\author{
K.W. $\mathrm{Ng}^{1}$ and Joseph C. H. So ${ }^{1}$ \\ ccmaggie@hkcc-polyu.edu.hk; ccso@hkcc-polyu.edu.hk \\ ${ }^{1}$ Hong Kong Community College, Hong Kong Polytechnic University
}

\begin{abstract}
This paper examines the correlation between curriculum reforms and the development of generic competencies among Hong Kong tertiary students (or secondary leavers who were admitted to Associate Degree and Higher Diploma). A total number of 3626 freshmen completed a set of self-assessment questionnaires, which were used to analyse the correlation between five generic competencies, across three academic years from 2010 to 2012. Five of the generic competencies, which were highlighted in the proposed new three-year New Senior Secondary (NSS) academic structure, were measured and compared between students from different academic backgrounds. The finding of the study indicated significantly higher scores in generic competencies for the traditional Hong Kong Advanced Level Examination (HKALE) secondary school curriculum in 2012 compared to earlier cohorts, whilst in general no significant difference was found between students from the traditional curriculum and the new academic structure of the Hong Kong Diploma of Secondary Education (HKDSE) in the mixed 'double cohort' year of 2012. The result points to the potential early impact of NSS on students' generic skill development across both the old and new curriculum.
\end{abstract}

Keywords: curriculum reform Hong Kong, senior secondary education, generic skills, college education.

\section{Introduction}

Major curriculum reform is initiated by governments to address, inter alia, the global marketplace and social change. In turn, each reform leads to adjustments of associated curricula, thereby enabling students to meet the challenges of globalization, international competition, and the knowledge-based economy. In 2001, in order to better prepare students' competitiveness in the face of rapid economic growth in China and other parts of the world in the $21^{\text {st }}$ century, the Hong Kong Curriculum Development Council proposed a reform of the curriculum for secondary and tertiary education which focused on students' whole-person development: an emphasis that responded to the growing cry for generic skills development in global education.

The new curriculum framework-a three-year New Senior Secondary (NSS) academic structure-aims to provide more opportunities for students to explore their aptitudes and potential through multidisciplinary learning experiences. In order to achieve this, the senior secondary and higher education system was restructured from the traditional curriculum 
(seven years of secondary plus three years of tertiary education) to a new academic syllabus of six years of secondary plus four years of tertiary education. Previously, the traditional system functioned as a dual selection and filtering mechanism. The first public examinations at the end of Form Five, known as the Hong Kong Certification of Education Examination (HKCEE), filtered one-third of the students into the two senior secondary years to progress their education and sit the second public examination, at the end of year seven. Known as the Hong Kong Advanced Level Examination (HKALE), this provided the University admission qualification. Hence, students from the traditional system were required to sit two separate examinations for university admission and approximately onethird of HKCEE examinees could continue their HKALE studies; whilst students under the NSS systems are required to take only one public examination known as the Hong Kong Diploma in Secondary Education (HKDSE) at the end of Form six. This structural change in the secondary school system was followed by a modification in extending the higher education system from a three-year to a four-year undergraduate curriculum. The chief concern behind such reform lies in the focus on nurturing students' all-round skills and learning attitude.

\section{Literature review and context}

The prime task of education in the globalization era is to nurture the younger generation as lifelong learners (Bates, 2002), and the school curriculum has played an increasingly important role in teaching generic skills, which are essential in the knowledge generation (Benjamin et al., 2012). An international city such as Hong Kong cannot afford to lag behind in the quest for quality education in response to globalization and must therefore engage in the ongoing review of the education curriculum (Chen, 2001; Mok \& Chan, 2002). Curriculum reform is a long term and difficult process towards the improvement of teaching and learning so as to achieve continuous development of students in the new education system. One of the key factors in making curriculum reform a smooth and successful transformation is the combined efforts of different parties. Researchers have been trying to examine the impact of such wholesale changes of secondary and higher education in Hong Kong and have contributed some useful discussions. For instance, Fullan (2001), discussed the importance of the involvement of different parties including principals, teachers, and students on educational change. Successful implementation of educational reforms actually hinges on these parties. The curriculum reform can help secondary and tertiary students develop a variety of skills: adaptability, creativity, independent thinking and life-long learning capabilities. Thus, the relationship between education reform and the holistic development of younger generations with a variety of skills and attitudes which will equip them to compete globally, has become more important than ever.

\section{Review of recent education curriculum reform in Hong Kong}

The reforms of this study are not the first major amendments that the Hong Kong government has called for of the secondary school curriculum. After the implementation of nine years of compulsory education from 1978, there were increasing concerns that education policies be focused on enhancing school quality and effectiveness (Tsang, 1997). In the late 1990s, the government introduced the Direct Subsidy Scheme which aimed to offer flexibility in management and curriculum development to semi-private and private schools (Education Commission, 1998; Yuen, Cheung, \& Wong, 2012). However, the public schools constituted the majority in the sector and reforms would be needed if changes were to cover the mass education population (Yuen, Cheung, \& Wong, 2012). At the turn of the century, the then Chief Executive of Hong Kong SAR Tung Chee-hwa proposed a major educational reform and requested that the Education Commission comprehensively review the academic structure, the curricula and the assessment mechanisms. The resulting report in 2000 was titled 'Learning for Life, Learning Through Life: Reform Proposals for the Education System in Hong Kong' (Chan, W., 2010). The 
Education Commission openly stated the urgency to carry out an overhaul of the Hong Kong education system, citing 'that learning is still examination driven', and 'school life is usually monotonous' which hindered learning effectiveness. It thus proposed a reform based on the following principles: student-focused, no loser, quality, life-wide learning, and society-wide mobilization (Yuen, Cheung, \& Wong, 2012). Follow-up consultation was conducted by the Curriculum Development Council at the end of 2000 which suggested a restructuring of the secondary school curriculum which, for the first time, explicitly emphasised the development of general skills in the student learning process. Nine generic skills were identified as learning outcomes: collaboration skills; communication skills; creativity; critical thinking; information technology skills; numeracy skills; problem-solving; self-management; study skills (Curriculum Development Council, 2000). It became the prototype of the New Senior Secondary (NNS) curriculum to be implemented later.

\section{Generic skills development under the NNS curriculum}

Whole-person development, mainly cultivated by the development of generic skills, has constantly been highlighted in government documentation and reports on the new education reform, which was outlined in the NNS. The key components of NNS, implemented since 2009, include eight Key Learning Areas (Chinese language, English language, Mathematics, Science, Technology, Arts, Physical, and Personal, Social and Humanities), together with the cultivation of Generic Skills and Values and Attitudes, which was considered a whole-person development (Education Bureau, 2010). Upper secondary students taking the NSS curriculum are now required to participate in a new assessment framework within three years, including four core subjects (Mathematics, English language, Chinese language and Liberal Studies), two or three elective subjects, one component of school-based assessment, and Other Learning Experiences (OLE). The NSS curriculum incorporates a new compulsory subject of Liberal Studies which aims to enhance students' awareness of contemporary social issues through encouraging self-directed learning, critical thinking, and an understanding of the role of the individual in society (Curry, 2012). Moreover, the implementation of a new component of school-based assessment and the OLE, which forms an integral part of the curriculum, aims to ensure the necessary exposure of students for a broad and balanced curriculum and nurture whole-person development (Education Bureau, 2010). Its aim is to strengthen students' generic skills with the flexible learning arrangement, which aligns with the primary objectives of the entire curriculum reform. Students now undertake 405 hours of extra-curricular activities within the three years of NSS curriculum, and they also complete a Student Learning Profile (SLP). The 405 hours benchmark occupies 15 per cent of the total curriculum time and must be allocated to five categories in the following distribution: Moral and Civic Education, Community Service and Career-related Experiences (total 135 hours altogether), Aesthetic Development (135 hours) and Physical Development (13 hours). These new components of the New Senior Secondary curriculum framework aimed to enable students to attain the following seven learning goals for whole-person development and stretch the potential of each student to:

1. be bi-literate and trilingual with adequate proficiency;

2. acquire a broad knowledge base, and be able to understand contemporary issues that may impact on their daily life at personal, community, national and global levels;

3. be an informed and responsible citizen with a sense of global and national identity;

4. respect pluralism of cultures and views, and be a critical, reflective and independent thinker;

5. acquire information technology and other skills as necessary for being a life-long learner;

Ng, K.W., \& So, J.C. (2017). Impact of secondary education reform on tertiary students' generic competencies: A case-study of associate degree freshmen in Hong Kong. Journal of Teaching and Learning for Graduate 
6. understand their own career/ academic aspirations and develop positive attitudes towards work and learning; and

7. lead a healthy life-style with active participation in aesthetic and physical activities (Curriculum Development Council, 2009).

These learning goals, and the new curriculum as a whole, emphasise the improvement in generic competencies of students through a non-traditional classroom learning experience, designed to prepare them for an increasingly globalized and rapidly changing world.

Echoing the Education Commission report, the Education and Manpower Bureau (2005) stated clearly that they intended to implement different plans to shift from over-emphasising academic studies to focus on whole-person development. The action plans were eventually adopted by pioneer schools in Hong Kong, using school publicity, community promotion, and external review to facilitate the achievement of generic skills including collaboration, communication, creativity, critical thinking, IT, problem-solving, self-management, and study skills (Chan, 2010; Cheng, 2009; Law, 2003), before its full implementation. Such a focus on generic skills and holistic development was a watershed that marked the difference between students from the traditional HKALE curriculum and those from the HKDSE curriculum.

Research has since been conducted to study the early impact of this new curriculum reform (Chan, 2010; Chan \& Luk, 2013; Yuen, Cheung, \& Wong, 2012). In particular, Yuen, Cheung and Wong (2012) pointed out that the implementation of curriculum reform at school level, and subsequently students' learning experiences, were subject to the principals' and teachers' agreement on teaching approaches and the schools' objectives. There has also been increasing attention on the impact of individual subjects. Liberal Studies, a new subject which was presumed to be a major training in several key generic skills, fell short of expectations in terms of finding the right balance between curriculum design and implementation (Fok, 2016). Yeung, Lee and Lam (2012) discussed the teachers' perception about the NSS senior secondary science curricula, and the many challenges they faced including assessment of learning outcomes and skills development. Similar studies were conducted to provide a critical analysis of the English language components of the NSS curriculum with evaluation from both teachers' and students' perspectives (Carless \& Harfitt, 2013), and also of mathematics (Leung, Leung, \& Zuo, 2014).

More importantly, it is worth considering the development of the generic skills of students to reflect the impact of the reforms. Cheung and Lau found an increase in the scores on creativity under the NSS curriculum reform (Cheung \& Lau, 2013), which matched the major goal of NSS. Also, Yuen, Cheung and Wong (2012) reviewed the first phase of the NSS curriculum reform. They found that developing generic skills to prepare students to compete the challenges has become the distinguishing feature of education reforms from the school principals' perspective. However, the progress made by secondary students was perceived to be less significant than their primary counterparts, as frontline teachers and panel heads did not believe that secondary students made huge improvement in generic skills. In particular, they viewed the progress in critical thinking and self-learning abilities less favourably compared to the development in IT, reading habits and healthy lifestyle (Yuen, Cheung, \& Wong, 2012). Another study on the NSS mathematics curriculum showed that a lack of teaching and learning strategies, and comprehensive assessment forms, hindered the nine generic skills development among students within the curriculum framework (Leung, Leung, \& Zuo, 2014). 
The new secondary curriculum reform also brings in new challenges for the tertiary education sector. Since students from both the old and new secondary education system completed their studies together in 2012 (with HKALE the last year on offer, and also the first batch for HKDSE), two cohorts of students would be competing together for entry to tertiary education in the same academic year. Under such circumstances, which was called 'double cohort' or 'dual cohort', where HKALE and HKDSE students studied concurrently, both groups of students were nurtured in the same schools despites going through dissimilar curricula, leading to a shared school life and learning experience. This required careful curriculum design from the tertiary education sector, since their education backgrounds, including the breadth and depth of content knowledge and skills, and learning experiences, might be different. Colleges and universities needed to respond to their seemingly distinct education backgrounds-yet perhaps mutually affected learning experience-and adjusted their curricula and co-curricular activities accordingly, so as to benefit both groups of students. Hence, our study of the first batch of HKDSE graduates, along with the comparison of HKALE students from 2010 to 2012 who studied alongside the HKDSE counterparts, will be a timely effort to evaluate of the effect of the new curriculum on students' holistic development.

More importantly, such intense competition for university admission by both HKALE and HKDSE groups of students has also produced a large number of tertiary students who went through an alternative study pathway. Whilst the top students were directly admitted to universities through outstanding public examination results, there was a large portion of secondary graduates who had satisfied the minimum entry requirement for local universities, yet were unable to obtain places in undergraduate programs. They took an alternative route of community colleges, which offered associate degree programs that prepared them for further undergraduate study. These students represented the average to above-average performers, albeit not outstanding, in both HKALE and HKDSE/NSS curriculum, and their learning outcomes and generic skills development would be useful in evaluating the overall development among the generation.

In the light of NNS's goal of cultivating generic skills, which are rapidly gaining attention in the tertiary education sector around the globe, it is useful to examine its development as an indication of how students progressed from two different secondary education systems and improved after finishing the early years of tertiary education. Also termed as 'transferable skills' or 'generic attributes', these skills are in nature multifunctional and, once acquired, can be applied strategically in different learning disciplines and working situations (Barrie, 2006; Chamorro-Premuzic, 2010; Tait \& Godfrey, 1999). The assumption is that, if the new education system does have an effect on students' overall growth, students from the NSS would at least possess better awareness on, if not better development in, generic skills. Hence, an enquiry into their generic competency will provide useful information for further research into the characteristics and needs of secondary students in forthcoming years under the new NNS curriculum.

\section{Methodology}

\section{Research questions}

In investigating whether the new curriculum provides a better generic skills development environment for students than the old curriculum, it is useful to trace back to the generic skills competencies from the earlier graduates of HKALE to the latest in HKDSE. The freshmen of college students (i.e. immediate graduates of secondary education) were selected for this purpose of comparing their performances with the latest graduates.

The central research questions included the following:

Ng, K.W., \& So, J.C. (2017). Impact of secondary education reform on tertiary students' generic competencies: A case-study of associate degree freshmen in Hong Kong. Journal of Teaching and Learning for Graduate 
1. Did HKALE students in the 'double cohort' show better generic skills development than their earlier generations?

2. Did NSS students undertaking HKDSE show better generic skills after their graduation from secondary education compared to their HKALE counterpart in the same cohort (i.e. 'double cohort' in 2012)?

\section{Background}

In this study, we investigated students from a community college affiliated with a largescale tertiary institution in Hong Kong from 2010 to 2012. The college which was multidisciplinary in nature, offered two-year associate degree and higher diploma programs across various disciplines (arts, science, social sciences, business and a number of specialised areas e.g. design) for local students after their graduation from secondary education. Students who enrolled in the college must have met the minimum entry requirements: Pass in one A-Level subject or two AS-Level subjects in Hong Kong Advanced Level Examination (HKALE) or equivalent qualifications. As for students from the new Hong Kong Diploma of Secondary Education (HKDSE), i.e. NSS curriculum, they must have obtained Level 2 or above in five HKDSE subjects including English Language and Chinese Language. Most students choose to pursue senior-year undergraduate studies after their graduation and in most cases they enrol in undergraduate programs in the cognate disciplines of their previous qualification.

Students were required to complete 60 credits throughout their study, among which 60 per cent were 'general education' subjects covering areas in language, creative and critical thinking, quantitative analysis and information technology literacy. The remaining 40 per cent of credits were discipline-related subjects which were designed to enhance students' specific skills and knowledge in their subsequent academic discipline (science, computer and information technology, business, humanities, design, etc). In addition, students were strongly encouraged to actively take part in over 300 co-curricular student activities being offered by the college as part of their tertiary education learning experience through an award system.

\section{Sample}

Participants were randomly selected from students who commenced their studies in three consecutive academic years from 2010 to 2012; thus the survey was carried out in three phrases. Participants were all freshmen enrolled in 35 associate degree programs offered by the college. A total number of 1376 freshmen, who had enrolled in the first year of a twoyear associate degree program within three months during the 2010/11 academic year, were surveyed in October 2010. For the 2011 cohort, a total of 933 students participated in the survey which was conducted from September to October in 2011 of the 2011/12 academic year. A further 1317 freshmen were recruited to conduct the survey in the 'double cohort' year of 2012 in October 2012, among which 817 (62.0\%) were graduates from the traditional HKALE curriculum, whilst 500 (38.0\%) were graduates of the new HKDSE curriculum.

\section{Measure}

The survey adopted a set of self-assessment inventory-the Self-Assessment of All-Round Development (SAARD) Questionnaire-to assess the generic competencies of respondents (Fung, Lee, Kwan, \& Wong, 2006; Fung, Lee, \& Wong, 2007). One reason for choosing SAARD was its relevance to the local context, as it was designed by and adopted to evaluate the generic skills for students in other local universities. Another reason was its reliability and validity (Fung et al., 2007) in addition to providing a comparatively comprehensive coverage on most generic skills that concern educators and policy makers 
today. It consisted of 56 statements covering 14 areas of generic competencies, which were grouped into five major domains:

1. social skills (communication, interpersonal effectiveness, leadership, teamwork);

2. social and cultural awareness (cultural appreciation, global outlook, social and national responsibility);

3. intellectual development (creative thinking, critical thinking, problem solving);

4. physical and psychological development (EQ and psychological wellness, healthy lifestyle); and

5. aspiration of learning (entrepreneurship, lifelong learning).

As the focus of this study was the analysis of the early impact of secondary education reform on tertiary students' generic skills, the skills that were most related to the nine generic skills stated by the Curriculum Development Council (2009) formed the basis of the study. Consequently five generic competencies were measured: social and national responsibility, cultural appreciation, global outlook, critical thinking and healthy lifestyle, which align with the learning goals of the Senior Secondary curriculum framework. These five generic competencies match most of the seven core learning goals of whole-person development set out by the Curriculum Development Council in 2009 (point 2 for Global outlook; point 3 for Social and national responsibility; point 4 for Critical thinking as well as Cultural Appreciation; point 7 for Healthy lifestyle).

The SAARD is a 7-point Likert-type scale self-assessing questionnaire, asking participants to reflect upon how well the respondent believed he or she was capable of accomplishing the statements ( $1=$ not well at all; $7=$ very well). Each statement assessed only one area of generic competency, and each domain of generic competency consisted of 4 statements. All statements were listed in random order. Points marked in each statement were converted into scores (multiplied by 4), resulting in a minimum of 4 marks and maximum of 28 marks for each statement. The score of each generic competency was the mean score of all four statements, and all four statements must be answered for that particular generic competency to be considered a valid assessment. If one or more of the statements of a generic competency was not answered by the respondent or deemed invalid, the mean score of that particular generic competency for that particular respondent would not be calculated and counted towards our analysis. The current study analyses five out of the 14 generic competencies of the entire SAARD, as they were highly related to some of the core learning objectives of the HKDSE curriculum reform. They will be used to measure the holistic development of students to illuminate outcomes of the new curriculum. These five generic skills are namely: social and national responsibility, cultural appreciation, global outlook, critical thinking, and healthy lifestyle.

The confidentiality of data collected was ensured to the students, as their personal identities were not recorded, and only their year of entry and programs enrolled would be acquired during the surveys. They were informed about the research and their rights before agreeing to participate, and could withdraw from the survey anytime they wished. They were also reassured that their responses in both surveys would not affect any assessment in any subjects throughout their studies, nor would they be disclosed to any program leaders or staff members who were responsible for handling marking and grading of student results.

\section{Results}

Questionnaires from four groups of students across three cohorts who entered the college from 2010 to 2012 as freshmen were analysed in this study, and their mean scores compared across five generic competencies to determine the possible impact of education reforms on their holistic development. The five generic competencies studied across the three different cohorts of freshmen were: social and national responsibility, cultural 
appreciation, global outlook, critical thinking, and healthy lifestyle, which were aligned with the nine competencies stated by the new curriculum reform.

\section{Comparison of freshmen from HKALE (2010-2012 cohort)}

In order to assess if there was variation between students coming from the same secondary education system before the implementation of the new curriculum, the mean scores on five generic competencies among freshmen from the 2010 and 2011 cohort, as well as 2012 cohort (i.e. 'double cohort') students who graduated from the HKALE curriculum, were observed and compared. The mean scores and standard deviation of 5 generic competencies across these three groups of student is shown in Table 1.

Table 1: Descriptive of Five Generic Competencies between Freshmen from 2010 to 2012 under the HKALE Education Curriculum in SAARD Survey

\begin{tabular}{|c|c|c|c|}
\hline Variable & $N$ & $M$ & SD \\
\hline \multicolumn{4}{|c|}{$\begin{array}{l}\text { Social \& National } \\
\text { Responsibility }\end{array}$} \\
\hline 2010 & 1361 & 19.27 & 3.52 \\
\hline 2011 & 930 & 20.10 & 3.41 \\
\hline 2012 & 815 & 20.99 & 3.23 \\
\hline \multicolumn{4}{|c|}{ Cultural Appreciation } \\
\hline 2010 & 1336 & 18.88 & 4.06 \\
\hline 2011 & 927 & 19.10 & 4.40 \\
\hline 2012 & 808 & 19.66 & 4.39 \\
\hline \multicolumn{4}{|c|}{ Global Outlook } \\
\hline 2010 & 1369 & 18.72 & 3.60 \\
\hline 2011 & 929 & 18.84 & 3.78 \\
\hline 2012 & 813 & 19.53 & 3.73 \\
\hline \multicolumn{4}{|c|}{ Critical Thinking } \\
\hline 2010 & 1364 & 19.22 & 3.00 \\
\hline 2011 & 932 & 19.58 & 2.82 \\
\hline 2012 & 811 & 20.27 & 2.78 \\
\hline \multicolumn{4}{|c|}{ Healthy Lifestyle } \\
\hline 2010 & 1363 & 18.68 & 3.81 \\
\hline 2011 & 930 & 18.95 & 4.03 \\
\hline 2012 & 817 & 19.43 & 3.93 \\
\hline
\end{tabular}

\section{Social and national responsibility}

Corresponded to the learning goal of 'to be an informed and responsible citizen with a sense of global and national identity' in the NSS curriculum. Table 1 indicated that there was a gradual increase of scores from 2010 to 2012 in students' sense of social and national responsibility. Freshmen from the 2010 cohort received a mean score of 19.27 ( $S D=3.52)$, compared to $20.10(S D=3.41)$ in 2011 and $20.99(S D=3.23)$ in 2012 cohort. 
This illustrated a continuing improvement in the sense of social and national responsibility among students.

\section{Cultural appreciation}

Corresponded to the learning goal of 'to respect pluralism of cultures and views, and be a critical, reflective and independent thinker' in the NSS curriculum. Table 1 showed that freshmen in the 2010 cohort received a mean score of $18.88(S D=4.06)$ in their cultural appreciation, which was similar to freshmen in $2011(M=9.10, S D=4.40)$. Freshmen in 2012 , on the other hand, had a mean score of $19.66(S D=4.39)$, which was higher than the previous two cohorts.

\section{Global outlook}

Corresponded to the learning goal of 'to acquire a broad knowledge base, and be able to understand contemporary issues that may impact on their daily life at personal, community, national and global levels' in the NSS curriculum. The result indicated that there was a similar trend in the development of global outlook as well as their scores in cultural appreciation. Table 1 showed that freshmen in the 2010 cohort received a mean score of $18.72(S D=3.60)$, and those in 2011 had similar scores $(M=18.84, S D=3.78)$. Freshmen in 2012 , however, appeared to have a higher mean scores of $19.53(\mathrm{SD}=3.73)$ compared to the previous two cohorts.

\section{Critical thinking}

Corresponded to the learning goal of 'to respect pluralism of cultures and views, and be a critical, reflective and independent thinker' in the NSS curriculum. Table 1 indicated that there was also a gradual increase of scores from 2010 to 2012 in the aspect of critical thinking. Freshmen from 2010 cohort obtained a mean score of $19.22(\mathrm{SD}=3.00)$, and was increased to $19.58(S D=2.82)$ in the 2011 cohort and 20.27 (SD=2.78) in the 2012 cohort. This illustrated a continuing improvement across three years.

\section{Healthy lifestyle}

Corresponded to the learning goal of 'to lead a healthy life-style with active participation in aesthetic and physical activities' in the NSS curriculum. Table 1 showed that the scores between freshmen in $2010(M=18.68, S D=3.81)$ and those in $2011(M=18.95, S D=4.03)$ were similar. However, freshmen in 2012 had a mean scores of 19.43 (SD=3.93), which was higher than the previous two cohorts.

In order to compare the mean scores of 5 generic competencies among freshmen from the same HKALE background, a one-way between-subject ANOVA was conducted on scores of each generic competency. The result found that there were significant differences on all five generic competencies at the $p<.05$ level for three groups of freshmen from 2010 to 2012. For social and national responsibility, significant statistical difference was found between three groups of freshmen $[F(2,3103)=65.629, p=.000]$. Similar results were also found on the mean scores of other four generic competencies: cultural appreciation $[\mathrm{F}(2,3068)=8.451, \mathrm{p}=.000]$, global outlook $[\mathrm{F}(2,3108)=12.826, \mathrm{p}=.000]$, critical thinking $[F(2,3104)=33.186, p=.000]$, and healthy lifestyle $[F(2,3107)=9.525, p=.000]$.

Since significant differences were found in the means scores of all five generic competencies between freshmen from three different years of entry, post hoc analyses were conducted to assess further differences amongst groups in these five generic competencies. Pairwise comparisons among the three groups of freshmen were conducted using Bonferroni with the significant level at 0.05. The post hoc analyses of 5 generic competencies by Bonferroni across these three groups of student are shown in Table 2. 
Table 2: Post Hoc Comparisons by Bonferroni of Five Generic Competencies between Freshmen from 2010 to 2012 under the HKALE Education Curriculum in SAARD survey $(n=3118)$

\begin{tabular}{|c|c|c|c|c|c|}
\hline Variable & Cohort (I) & Cohort (J) & MD & SE & $p$ \\
\hline \multicolumn{6}{|c|}{$\begin{array}{l}\text { Social \& National } \\
\text { Responsibility }\end{array}$} \\
\hline & 2011 & 2010 & $.82814^{*}$ & .14522 & $.000^{*}$ \\
\hline & & 2012 & $-.89141^{*}$ & .16378 & $.000^{*}$ \\
\hline \multicolumn{6}{|c|}{ Cultural Appreciation } \\
\hline & 2011 & 2010 & .21352 & .18193 & .722 \\
\hline & & 2012 & $-.56117^{*}$ & .20483 & $.019^{*}$ \\
\hline \multicolumn{6}{|c|}{ Global Outlook } \\
\hline & 2011 & 2010 & .11865 & .15680 & 1.000 \\
\hline & & 2012 & $-.68314^{*}$ & .17716 & $.000^{*}$ \\
\hline \multicolumn{6}{|c|}{ Critical Thinking } \\
\hline & 2011 & 2010 &. $.35726^{*}$ & .12306 & $.010^{*}$ \\
\hline & & 2012 & $-.68817^{*}$ & .13906 & $.000^{*}$ \\
\hline \multicolumn{6}{|c|}{ Healthy Lifestyle } \\
\hline & 2011 & 2010 & .27472 & .16616 & .295 \\
\hline & & 2012 & $-.47968^{*}$ & .18733 & $.031^{*}$ \\
\hline
\end{tabular}

\section{Social and national responsibility}

Based on the Bonferroni result, it was found that the mean scores in social and national responsibility was significantly different between 2010 and 2011 freshmen $(M D=.83, p<.05)$ and also between 2011 and 2012 freshmen $(M D=.89, p<.05)$. Hence, 2012 freshmen scored significantly higher in social and national responsibility than those in 2011 , who also possessed a significantly higher mean score compared to their 2010 counterparts. This illustrated a continuing increase across three years among HKALE students.

\section{Cultural appreciation}

The Bonferroni result illustrated that the mean scores in cultural appreciation between 2010 and 2011 freshmen (MD=.21, $\mathrm{p}=.722$ ) was statistically insignificant. However, significant difference was found between 2011 and 2012 freshmen $(M D=.77, p<.05)$. Therefore, it was found that HKALE students from 2012 cohort possessed significant difference from their counterparts in previous two years.

\section{Global outlook}

The Bonferroni result of global outlook showed a similar trend found in cultural appreciation. It was found that the mean scores in global outlook between 2010 and 2011 freshmen $(M D=.19, p=1.000)$ was statistically insignificant. However, there was significant difference between 2011 and 2012 freshmen $(\mathrm{MD}=.68, \mathrm{p}<.05)$. Therefore, it was found that HKALE students from 2012 cohort possessed significant higher mean scores from their counterparts in both 2010 and 2011. 


\section{Critical thinking}

Table 2 indicated that, according to the Bonferroni result, there were statistically significant differences between three groups of students in critical thinking. The mean scores was significantly different between 2010 and 2011 freshmen $(M D=.38, p<.05)$, and also between 2011 and 2012 freshmen $(M D=.69, p<.05)$. Hence, 2012 freshmen scored significantly higher in social and national responsibility than freshmen in 2011, who were also scored significantly higher compared to their 2010 counterparts. This demonstrated that there was a continuing increase across three years among students from HKALE background in terms of the generic competency of critical thinking.

Healthy lifestyle

The Bonferroni result in Table 2 showed that the mean scores in cultural appreciation between 2010 and 2011 freshmen $(M D=.21, p=.722)$ was statistically insignificant. However, it was found that there was significant difference between freshmen from the 2011 and 2012 (MD=.77, $\mathrm{p}<.05)$. Therefore, it was observed that HKALE students from 2012 cohort possessed significant higher mean scores in the generic competency of healthy lifestyles from their counterparts in previous two years.

\section{Comparison of freshmen from HKALE and HKDSE}

Further analysis was conducted to determine whether the scores in these generic competencies would be different from those who were directly affected by the new HKDSE curriculum. The complete independent-samples t-test result of these five generic competencies in the SAARD survey on freshmen in 2012, in accordance to secondary curriculum, is shown in Table 3.

Table 3: Independent Samples $t$ Test of Five Generic Competencies in Relation to 2012 Freshmen from HKALE and HKDSE in SAARD survey $(n=1316)$

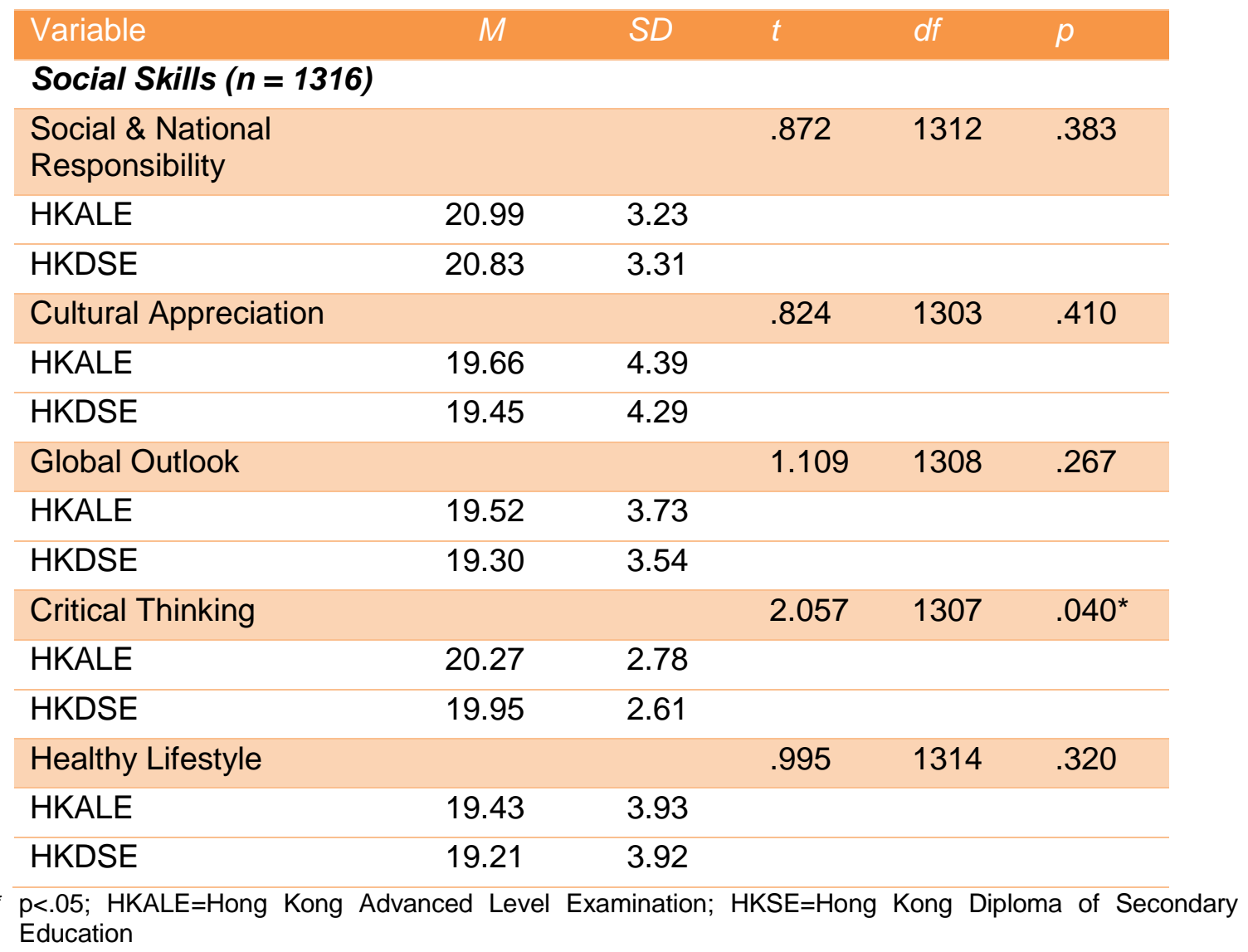

Ng, K.W., \& So, J.C. (2017). Impact of secondary education reform on tertiary students' generic competencies: A case-study of associate degree freshmen in Hong Kong. Journal of Teaching and Learning for Graduate Employability, 8(1), 106-122. 


\section{Social and national responsibility}

Table 3 indicated that no significant difference could be found among two groups of freshmen in terms of social and national responsibility. The mean scores $(t=.872, p=.383)$ between freshmen with HKALE and HKDSE background were found insignificant.

\section{Cultural appreciation}

The result also showed no significant difference in the generic competencies of cultural appreciation. The mean scores o $(\mathrm{t}=.824, \mathrm{p}=.410)$ between freshmen with HKALE and HKDSE background insignificant.

\section{Global outlook}

The result again indicated that no significant difference was found between the mean scores of these two groups in global outlook $(t=1.109, p=.267)$.

\section{Critical thinking}

The result showed that freshmen graduated from the HKALE curriculum scored significantly higher in critical thinking $(M=20.27)(t=2.057, p<.05)$ than their counterpart who graduated from the HKDSE curriculum in the same year.

\section{Healthy lifestyle}

The difference on mean scores between the two groups was found insignificant in this area. Freshmen from the HKALE curriculum did not score significantly higher than their HKDSE counterpart $(t=.955, p=.320)$.

\section{Discussion}

The following section discusses the results and findings in relation to the context of NSS curriculum in Hong Kong.

\section{Comparison of freshmen from HKALE (2010-2012 cohort)}

In summary, the statistical analyses showed that there was a general difference between freshmen from three different cohorts who took the HKALE curriculum for the last three consecutive years of the old curriculum. Regardless of the statistical difference between their counterparts in the 2010 and 2011 subgroups, freshmen in the 'double cohort' 2012 year, who graduated from the last year of the HKALE, scored significantly higher than the other two subgroups of students. Importantly, such significant difference was observed in all five generic competencies when compared to freshmen in previous two cohorts, which indicated that they had an overall better self-awareness and self-evaluation of these generic competencies. Since these five competencies were highlighted by the EDB as some of major generic skills for holistic student development in the new HKDSE curriculum, such significant improvement shown by HKALE students in this 'double cohort' year showed a possible impact of the NSS curriculum, as they might have also been affected by it despite not studying in the NSS curriculum themselves.

Before the implementation of the NSS curriculum, there had been calls for a new focus for secondary education which highlighted the development of generic skills during students' learning experiences, giving students a more holistic learning trajectory (Curriculum Development Council 2000). The introduction of nine generic competencies, cultivated through eight Key Learning Areas, the Other Learning Experiences (OLE) (Education Bureau, 2010) and the new Liberal Studies subject, put extra emphasis on the fostering of self-directed learning, critical thinking, creativity, and an understanding of the role of individual in society, all of which were reflect in earlier research (Cheung \& Lau, 2013; Curry, 2012). Despite reservation about the implementation strategies of the NSS and the challenges faced by frontline teachers (Leung, Leung, \& Zuo, 2014; Yuen, Cheung, \& 
Wong, 2012), our study shows that the new curriculum actually affected those who were studying under the old curriculum. HKALE students who studied together with their HKDSE counterparts in the same secondary schools might have benefited from sharing their learning experience in the school life, mutually affecting each other when participating in the informal curriculum and extra-curricular activities.

\section{Comparison of freshmen from HKALE and HKDSE}

In the light of such significant improvement in five generic competencies among the 'double cohort' freshmen who studied the HKALE curriculum, the comparison of results between two groups of students from this 'double cohort' would provide a useful indication, if not confirmation, of whether the NSS curriculum did affect students' generic skills development.

According to the analysis, there was no statistically significant difference in most generic competencies between tertiary freshmen from the old and new secondary education curriculum in 'double cohort' year of 2012. The only significant difference was found in critical thinking, which favoured the freshmen who graduated from the HKALE curriculum. Their mean scores in social and national responsibility, cultural appreciation, global outlook and healthy lifestyle, which were among other aspects of holistic development targeted by the NSS curriculum reform, were statistically insignificant. Hence, in summary, it can be concluded that the tertiary students who graduated from HKALE and HKDSE curricula in 2012 did not differ significantly in major aspects of holistic development apart from critical thinking.

Further analysis and discussion can be drawn from the results on both analyses. Firstly, the result proved that, despite not showing significant impact on the holistic development of HKDSE students as yet, the newly implemented HKDSE curriculum may have already affected the last cohort of HKALE students who studied alongside their HKDSE classmates in the secondary schools, which was also discussed earlier in the analysis of HKALE students across the last three years of the old curriculum. The fact that freshmen with a HKALE background in 2012 displayed unanimously significant improvement in most of the generic competencies when they commenced their tertiary studies may perhaps be credited to their better exposure and knowledge of holistic development by studying together with HKDSE students in the NSS curriculum.

The second observation goes back to the question of whether the new NSS curriculum offered better generic skills development to the first cohort of HKDSE students than the old curriculum. The result showed that, contrary to what might have been expected, no significant differences were found in four out of five generic components between students from HKALE and HKDSE, with critical thinking the only component that demonstrated a difference in favour of HKALE students. The overall mean scores by HKDSE students were also slightly lower, although regarded statistically insignificant, compared to their HKALE counterpart in each component. Thus, according to the result, HKDSE students did not possess the expected better self-awareness and development of holistic development than students from the HKALE prior to the education reform.

The result reiterates some of the observations in earlier research which cast doubts over the early impact of the NSS on student development in general, and can be explained by a number of factors. Chan and Luk explained in their research findings on Hong Kong curriculum reform that students accustomed to the traditional spoon-fed learning approach may find it difficult to adapt to the inquiry-based approach in the NNS curriculum, and may take years to learn and adopt a new mindset (Chan \& Luk,, 2013). Therefore, while HKALE students in 2012 had attained better awareness and development of these generic skills through a gradual immersion in the new school setting, HKDSE students faced a completely new curriculum which they were not familiar with. The learning goals and development of certain generic skills highlighted by the NNS curriculum may not demonstrate a sharp improvement of holistic development on HKDSE students, since they 
may need time to understand new learning objectives and pedagogies under a new educational framework that differs radically from their junior secondary education. Thus there may have been a premature expectation that the HKDSE students would outperform their HKALE counterparts in generic skills development.

Yuen, Cheung and Wong (2012) questioned the impact of cultural values on students when they adapt to a new curriculum, and further discussed the factors that would affect the successful implementation of the new curriculum reform (Cheung \& Wong, 2012). The current findings of the study indicated some early positive signs of improvement in the generic competencies under the curriculum reform, although collaboration between teachers, headmasters and students will be needed to strengthen the impact on the next generations of students. The educational reforms include school-based management, school-based curriculum and integrated curriculum; hence principals and teachers have to participate in different training programs, become familiar with the new system and meet certain requirements of this reform (Cheng, 2009; Cheung \& Wong, 2011). These parallel initiatives from the managerial and educational fronts provide room for improvement to the traditional HKALE students, and the NSS students, at the same time, can enjoy the initial benefits of the curriculum reforms.

Similarly Fok (2016) argued that the introduction of Liberal Studies as a compulsory subject did not have the expected impact on nurturing a variety of generic skills as it failed to find a right balance between curriculum design, school and teacher expectation, and implementation strategies. Similar problems could also be found in other subjects such as English and Mathematics (Carless \& Harfitt, 2013; Leung, Leung, \& Zuo, 2014). This resulted in the seemingly insignificant impact on the development of generic skills among HKDSE students, as shown in our results. It appears that nurturing generic skills through academic subjects needs better incorporation with the entire curriculum, which again depends on the transformation of cultural values of different stakeholders in accepting a new teaching philosophy and new pedagogies.

\section{Limitations}

There are, however, some limitations of this study. One possible limitation is that it reported the self-evaluation and self-awareness of tertiary students' generic competencies resulting from curriculum reform. The impact of the new curriculum reform was thus based on the perception of students themselves. Although the students' self-assessment plays an important role in the study of the curriculum reform, evaluations being conducted by their secondary teachers when they graduated from secondary schools would provide a fuller understanding of their generic skills development. Another limitation lies in the range of students. This study focused on the average to above-average secondary graduates, and excluded the elite students studying in the major universities, as well as those who struggled and performed below-par in the HKALE or HKDSE and thus did not attend tertiary education. Understanding their generic skills development from a number of perspectives and data sources would provide a more comprehensive evaluation of the NSS curriculum.

Several directions for future studies are suggested. For example, it would be useful to investigate the development of students' generic skills and attitudes over the long-term and consider the impact of these on student achievement. Similarly, the involvement of and collaboration between different stakeholders, including school management, frontline teachers and parents, should be examined to give more breadth to the study and therefore more comprehensively evaluate the impact of the new curriculum reform.

\section{Conclusion}

This paper has studied the generic skills of tertiary freshmen across three academic years (from 2010 to 2012) as a reflection of the impact of the NSS curriculum reform on secondary education students. The study was carried out in three phrases. Five generic 
competencies, which were highlighted as a focus in the NSS academic structure, were measured and compared between students from different academic backgrounds. The result of the study leads to several conclusions about generic competencies and their relation to the changing secondary education curricula in Hong Kong. First, the result indicated a gradual improvement in these five generic competencies in students across three years from 2010 to 2012 for the traditional Hong Kong Advanced Level Examination (HKALE) secondary school curriculum. The HKALE students in 2012 outscored previous cohorts with statistical significance on all five generic skills, which illustrated a stronger overall competency. Second, overall there was no significant difference found between students from the HKALE curriculum and the new academic structure of Hong Kong Diploma of Secondary Education (HKDSE) in 2012. It was suggested that they might be influenced by the students of HKDSE, despite not studying the same curriculum, but sharing school life and mutually influencing their learning experiences, which possibly led to a similar generic skills development trajectory and impact.

Curriculum reform requires constant feedback and review to enhance the effectiveness of the teaching and learning. The educational reforms under consideration have been implemented for ten years. It is the right time to conduct a thorough review of its progress, and research as such may lead to modifications or adjustments that can further improve the teaching and learning effectiveness for both educators and students. The Hong Kong Education Bureau and schools should provide quality professional development for their teachers and continuous review of the structure, curriculum and assessment to build the capacity to meet the requirements of the reform. The present study has examined the students' generic competencies of the first cohort of the curriculum reforms. Further studies will be valuable to investigate the continuous impact of this curriculum restricting.

\section{Acknowledgment}

The authors gratefully acknowledge the invaluable contributions of the Student Affairs Office of the Hong Kong Polytechnic University for authorizing the use of the SAARD questionnaires for the purpose of this survey. In addition, the research was subsidized by the Research Committee of the College of Professional and Continuing Education, without its generous contribution the project would not have been made possible. 


\section{References}

Barrie, S. (2006). Understanding what we mean by the generic attributes of graduates. Higher Education, 51, 215-241.

Bates, R. (2002). Administering the global trap: The roles of educational leaders. Education Management and Administration, 30(2), 139-56.

Benjamin, R., Klein, S., Steedle, J., Zahner, D., Elliot, S., \& Patterson, J. (2012). The case for generic skills and performance assessment in the United States and international settings (CAE-occasional paper 1). New York, NY: Council for Aid to Education.

Carless, D. R., \& Harfit, G. J. (2013). Innovation in secondary education: A case of curriculum reform in Hong Kong. In K. Hyland \& L. L. C. Wong (Eds.), Innovation and change in English language education, (pp. 172-185). Milton Park, Abingdon, Oxon: Routledge.

Chamorro-Premuzic, T., Arteche, A., Bremner, A. J., Greven, C., \& Furnham A. (2010). Soft skills in higher education: Importance and improvement rating as a function of individual differences and academic performance. Educational Psychology, 30(2), 221-241.

Chan, C. K. Y., \& Luk, L. Y. Y. (2013). Faculty perspectives on the ' $3+3+4$ ' curriculum reform in Hong Kong: A case study. International Education Studies, 6(4), 56-66.

Chan, J. K. S. (2010). Teachers' responses to curriculum policy implementation: Colonial constraints for curriculum reform. Educational Research for Policy and Practice, 9(2), 93-106.

Chan, W. (2010). A review of education reform-New Senior Secondary (NSS) Education in Hong Kong. International Education Studies, 3(4), 26-35.

Chen, E. (2001). The road to educational reform: New economy and new technology. Spring Drizzle, 79(1), 1-2 (in Chinese).

Cheung, P. C., \& Lau, S. (2013). A tale of two generations: Creativity growth and gender differences over a period of education and curriculum reforms. Creativity Research Journal, 25(4), 463-471.

Cheng, Y. C. (2009). Hong Kong educational reforms in the last decade: Reform syndrome and new developments. International Journal of Educational Management, 23(1), 65-86.

Cheung, A., \& Wong, P. M. (2011). Effects of school heads' and teachers' agreement with the curriculum reform on curriculum development progress and student learning in Hong Kong. International Journal of Educational Management, 25(5), 453-473.

Cheung, A., \& Wong, P. M. (2012). Factors affecting the implementation of curriculum reform in Hong Kong: Key findings from a large-scale survey study. International Journal of Educational Management, 26(1), 39-54.

Curry, J. M. (2012). Cultural challenges in Hong Kong to the implementation of effective general education. Teaching in Higher Education, 17(2), 223-230.

Curriculum Development Council, Learning to Learn, Lifelong Learning and Whole Person Development. Government Printer, Hong Kong. 2001.

Curriculum Development Council (2009). The student programme to achieve the vision of the new academic structure, whole-person development and life-long learning. Senior Secondary Curriculum Guide. Retrieved from http://cd1.edb.hkedcity.net/cd/cns/sscg web/pdf/eng/Booklet\%201\%20eng.pdf

Education Commission (1988). Education Commission Report No. 3, Education Commission, Hong Kong. 
Education Commission (2000). Learning for life, learning through life: Reform proposals for the education system in Hong Kong. Education Commission, Hong Kong.

Education Bureau (2010). New senior secondary curriculum other learning experiences: Parents' pamphlet. Retrieved from http://334.edb.hkedcity.net/doc/eng/OLEParentPamphlet.pdf

Education and Manpower Bureau (2005). The new academic structure for senior secondary education and higher education - action plan for investing in the future of Hong Kong. Government Printer, Hong Kong.

Fok, P. K. (2016). Liberal studies reform in Hong Kong secondary education: Contrasting desirability with feasibility. Educational Research for Policy and Practice, 15(3), 209230.

Fullan, M. (2001). The new meaning of educational change (3rd ed.). Teachers College Press: New York and London.

Fung, D., Lee, W., Kwan, K. P., \& Wong, S. L. P.(2006). Project on assessing the development of generic competencies of PolyU students-Report of findings. Hong Kong: Student Affairs Office and Educational Development Centre, Hong Kong Polytechnic University.

Fung, D., Lee, W., \& Wong, S. L. P. (2007). A new measure of generic competencies. Presented at the Key Competencies-Skills for Life 2007 Conference, July 12-13, 2007, London, UK.

Law, W.W. (2003). Globalization as both threat and opportunity for the Hong Kong teaching profession. Journal of Educational Change, 4(2), 149-179.

Leung, K. C., Leung, F. K. S., \& Zuo, H. (2013). A study of the alignment of learning targets and assessment to generic skills in the new senior secondary mathematics curriculum in Hong Kong. Studies in Educational Evaluation, 43, 115-132.

Mok, J., \& Chan, D. (2002). Globalization and education: The quest for quality education in Hong Kong. Hong Kong: Hong Kong University Press.

Tait, H., \& Godfrey, H. (1999). Defining and assessing competence in generic skills. Quality in Higher Education, 5(3), 245-253.

Tsang, W.K. (1997). The cult of market efficiency: The deep meaning of the ECR7. Occasional Paper No.3.Hong Kong: Hong Kong Institute of Educational Research, The Chinese University of Hong Kong.

Yeung, Y. Y., Lee, Y. C., \& Lam, I. C. M. (2012). Curriculum reform and restructuring of senior secondary science education in Hong Kong: Teachers' perceptions and implications. Asia-Pacific Forum on Science Learning and Teaching, 13(2), article $11,1-33$.

Yuen, T. W. W., Cheung, A. C. K., \& Wong, P. M. (2012). A study of the impact of the first phase of the curriculum reform on student learning in Hong Kong. International Journal of Educational Management, 26(7), 710-728. 